\title{
"A Alma, o Corpo e a Psicanálise"
}

O texto apresenta uma discussão sucinta sobre as relações entre Psicanálise e Psicossomática. Faz uma retrospectiva da evolução da concepção das práticas curativas, desde a paleo-medicina, passando por uma distinção entre medicina psicossomática e psicossomática psicanalítica, até uma proposta de superação do dualismo mente-corpo.

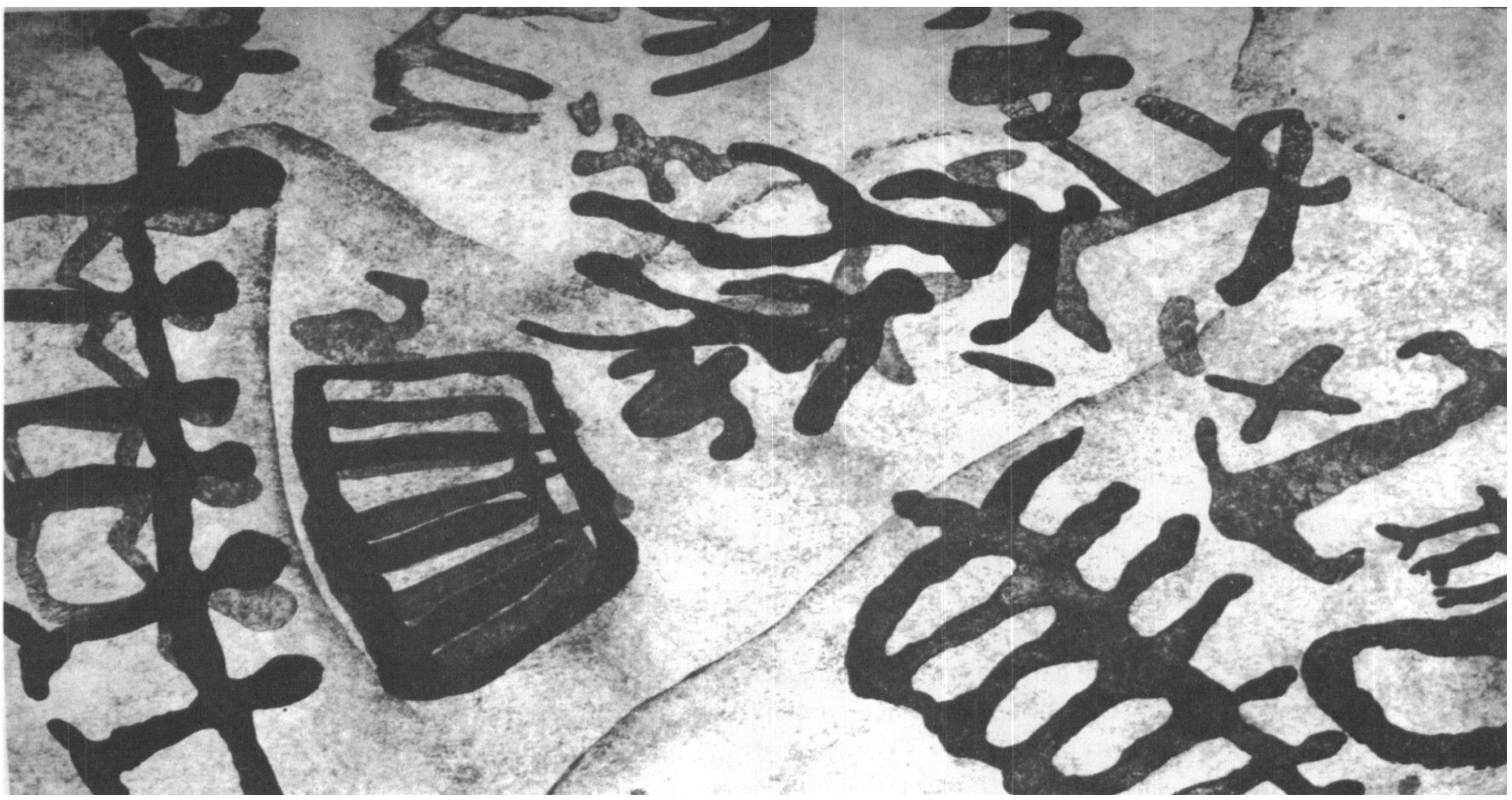

\section{$\mathbf{P}$}

sicossomática é uma nova especialidade da Medicina, um outro campo de aplicação para a Psicanálise e uma das mais fecundas áreas de interface para o desenvolvimento da pesquisa sobre o fenômeno humano. Nos últimos setenta anos, um grande número de trabalhos, tanto médicos, quanto vinculados à teoria e à clínica da Psicanálise, surgiram, propiciando uma série de desdobramentos que afetam o curso da prática médica em geral bem como levantam questões para os modelos de compreensão dos vários aspectos que tangem os processos do ser humano, na saúde, na doença, e na condução de sua experiência concreta de ser vivo, social e culturalmente determinado.

Abordaremos nesse trabalho três pontos, importantes para a localização da perspectiva em que nos situamos, e que permitem a especificação de uma abordagem psicanalítica para a Psicossomática. $O$ primeiro ponto diz respeito a uma breve revisão histórica da evolução da concepção psicossomática, acompanhando o trajeto das práticas curativas desde a Paleo-Medicina, ou Medicina ancestral, até o século XIX. O segundo ponto faz a diferenciação entre as duas tendências fundamentais em que se divide a Psicossomática, para as quais propomos as designações de Medicina Psicossomática e de Psicossomática Psicanalítica. Finalmente, apresentaremos um modelo para a representação do fenômeno psicossomático, que permite uma aproximação à desejável superação do dualismo corpomente.

\section{Lazslo Antonio Ávila}

Psicólogo

Psicanalista

Mestre e Doutor pela USP-Professor-adjunto da Faculdade de Medicina de São José do Rio Preto/SP 
"Deve-se notar que, neste sistema integrado, Saúde e devoção, harmonia e cirurgia, destino e significação, são pólos que regem o que o homem vive e crê, partiIhando com deuses e demônios a sua história" (Àvila, 1996)

\section{As práticas curativas ancestrais}

A pintura rupestre, onde o homem do Paleolítico ao Neolítico, entre 50.000 e 10.000 anos antes de Cristo, representou as primeiras expressões conhecidas de sua humanidade, continua trazendo inúmeras informações sobre a cultura humana dos primórdios da história. $\mathrm{Na}$ gruta dos Três Irmãos, na França, encontra-se a representação de um provável sacerdotemédico, vestido com peles de animais $\mathrm{e}$ envergando chifres de alce, datada, segundo os testes com carbono 14, de 35.000 anos. Segundo Lopes (1970), os registros arqueológicos demonstram a íntima relação entre as práticas religiosas e curativas na pré-história. A técnica primitiva da trepanação, na verdade uma sofisticada cirurgia em que uma parte do crânio era removida, visava, segundo esse autor, a propiciar que os "maus espíritos" fossem afugentados do doente.

No berço da Civilização, a Mesopotâmia, os curandeiros lutavam contra as doenças com encantamentos, considerando que as forças maléficas que se materializavam como doenças eram expressões do castigo ou vingança dos deuses ( Lopes, 1970,pp 30-31). Entre os assírios, a prática curativa incluía a cirurgia, a astrologia, drogas de origem vegetal e a interpretação dos sonhos do doente. Os principais pecados, causadores de doenças, eram: "Excitar o pai contra o filho e o filho contra o pai; excitar o amigo contra o amigo; entrar na casa do próximo; conquistar a mulher do amigo, dividir uma familia unida; desatender ao superior, e assim por diante"(Lopes,1970,p-38).

Observe-se que, nessa interessante enumeração, são os fatores básicos do convívio humano, a integração cultural, que estão em jogo, sendo a doença uma expressão da perturbação do viver. Como expressamos em outro trabalho: "Deve-se notar que, neste sistema integrado, Saúde e devoção, harmonia e cirurgia, destino e significação, são pólos que regem o que o homem vive e crê, partilhando com deuses e demônios a sua história" (Àvila, 1996).

Entre os egípcios, já se pode constatar a especialização, pois existiam, segundo
Heródoto, médicos que tratavam das diferentes partes e sistemas, de órgãos específicos, ou de conjuntos de sintomas. Praticantes de sofisticadas técnicas médicas e cirúrgicas, os egípcios legaram aos gregos muitos dos elementos que serão desenvolvidos pelos asclepíades, os médicos helênicos. Na obra de Hipócrates (ou dos muitos Hipócrates, pois segundo Lopes teriam existido muitos médicos com este mesmo nome) verifica-se o quanto da Medicina clássica se prendia a uma concepção ampla e integrada das doenças. Para o médico hipocrático, o organismo humano era considerado um microcosmos, inserido no universo maior que o regia. Dizia Hipócrates: "Para conhecer-se a natureza do homem é necessário conhecer-se a natureza de todas as coisas"(Lopes, 1970, p111).

\section{Da idade média à idade moderna}

Os princípios fundamentais da medicina grega, acrescentados da contribuição de Galeno e dos médicos romanos, formaram a base das técnicas curativas durante toda a ldade Média. O homem em interação com a natureza, seu corpo e seu espírito, inseparáveis, tal era a concepção desse período, como se pode constatar nesse documento, resgatado e comentado por Phillipe Ariès

"Uma idéia geral emanava da obra, idéia erudita que logo se tornou extremamente popular: a idéia da unidade fundamental da natureza, da solidariedade existente entre todos os fenômenos da natureza, que não se separam das manifestaçōes sobrenaturais. A idéia de que não havia oposição entre o natural e o sobrenatural pertencia ao mesmo tempo às crenças populares herdadas do paganismo, e a uma ciência tanto fisica quanto teológica. (...) Uma mesma lei rigorosa rege ao mesmo tempo o movimento dos planetas, o ciclo vegetativo das estações, as relaçōes entre os elementos, o corpo humano e seus humores, e o destino do homem".

(Ariès, 1986/1566, pp 34-35):

Com a grande revolução científica da idade moderna, muitas transformações advirão, mas a concepção médica permanece tributária de uma forma de representação das doenças e de sua causalidade onde corpo e espírito ainda 
estão intimamente unidos. Assim, por exemplo, Ettmüller, em 1691, descrevia como causas para as convulsões, alguns fatores que hoje seriam referendados pela moderna medicina, ao passo que outros seriam sem dúvida relegados, como conhecimentos supersticiosos, pré-científicos, ou francamente derrisórios: "a cólica nefrítica, os humores ácidos da melancolia, o nascimento durante um eclipse da Lua, a vizinhança das minas de metal, a cólera das amas de leite, os frutos de outono, a constipação, os caroços de néspera no reto e, de modo mais imediato, as paixões, sobretudo as do amor"

(Foucault,1972/1691 p222).

Porém, a distinção estabelecida por Descartes, entre a res cogitans e a res extensa, logo se traduzirá em fundamento para a apreensão do corpo como realidade objetiva, conduzindo à radical separação entre corpo e mente, que a Medicina dos séculos XVII e XVIII consagrará. Adotando a categorização que nasceu com a Botânica, a minuciosa descrição e classificação de todo o mundo natural, ao mesmo tempo que os princípios da experimentação das ciências físico-químicas, a Medicina passa a empregar os novos parâmetros que confluirão, no século XIX, com as grandes descobertas científicas dos fatores etiológicos de inúmeras doenças, e o desenvolvimentos de novos recursos diagnósticos e terapêuticos. A Medicina ingressa no século XX com a esperança de poder abordar, com a Biologia, a Física e a Química como retaguarda, e a tecnologia como aliada, a totalidade dos padecimentos humanos.

\section{A Esfinge}

Existe, todavia, uma doença, descrita há mais de 4.000 anos, e que parece não se curvar a todos os esforços diagnósticos e curativos da Medicina: trata-se da Histeria, entidade tão enigmática e tão exasperante, que inúmeros médicos, antigos e atuais, propõem que se abandonem todas as tentativas de compreendêla. Aliás, é exatamente a Histeria que vai dar surgimento a uma outra e revolucionária forma de pensar o sofrimento humano: a Psicanálise.

A Histeria parece confundir todas as fronteiras, $\mathrm{e}$ vai obrigar ao criador da Psicanálise à criação de um método próprio de investigação, método esse que é co-extensivo de suas formas de expressão. São as histéricas que inventam a Psicanálise, forçando, com seu desejo enigmático e demandante, que sua voz se faça ouvir, que seus sofrimentos "sem causa" sejam levados em conta, na mais intensa inserção do profissional que esteja buscando auxiliá-las. Freud pode fazer o gesto revolucionário, já esquecido pela Medicina de sua época, de ouvir sua paciente, e com isso trazê-la para o próprio centro de sua própria história e, assim, também, de seu processo terapêutico.

A Psicanálise, no entanto, e à sua revelia, vai contribuir para que a Medicina moderna faça mais profundo o fosso entre os fenômenos psíquicos e os somáticos, como se pode constatar em todas as tentativas atuais de encontrar fatores exclusivamente biológicos para compreender processos de doença, procurando "isolar" os fatores "não objetivos".

\section{As duas Psicossomáticas}

Na década de 1920 vão surgir, simultaneamente na Alemanha e nos Estados Unidos, pesquisadores interessados em aplicar a Psicanálise ao conhecimento dos determinantes das doenças. Em Nova York, a dra. Helen Dunbar e em Chicago, o grupo ligado a Franz Alexander fundam o que deve ser denominado como Medicina Psicossomática. Tal designação se aplica, pois a Psicanálise será empregada, por esses autores e muitos outros que os seguiram, como um meio terapêutico auxiliar do procedimento médico, e suas hipóteses e modelos teóricos funcionarão para esclarecer possíveis determinantes inconscientes para as doenças. Para a Medicina Psicossomática, como afirma Trillat, "o conflito não é específico":

"O que é específico, é a resposta fornecida por cada indivíduo em função de seu caráter, de suas tendências: a agressividade que não encontra meios de se descarregar no sistema de relação, vai tomar emprestada a via neuro-vegetativa $e$ provocar perturbações cardiovasculares. Noutros casos, a necessidade de dependência ou de proteção, se não satisfeitas, vão se traduzir em perturbações da esfera digestiva (úlcera, constipação, colite)." 
constipação, colite)."

A Medicina Psicossomática adota os mesmos critérios diagnósticos da Medicina, seus métodos, suas técnicas, seu procedimento de pesquisa, seus critérios de cura. A Psicanálise fornece para ela mais uma ferramenta, um meio de investigação daqueles fatores etiológicos "invisiveis", as emoçōes, o fator "subjetivo".

Muito diferente é a orientação da outra Psicossomática, a que propomos chamar de Psicossomática Psicanalítica. Para essa concepção o "subjetivo" não é um fator de causalidade, e o sintoma, qualquer sintoma, não é o que deve ser eliminado. Para a Psicanálise, o principal sintoma é o próprio Ego, e esse é visto como um "campo de batalha", como Freud propunha em 1917.

Não se sofre só no corpo, nem apenas psiquicamente.

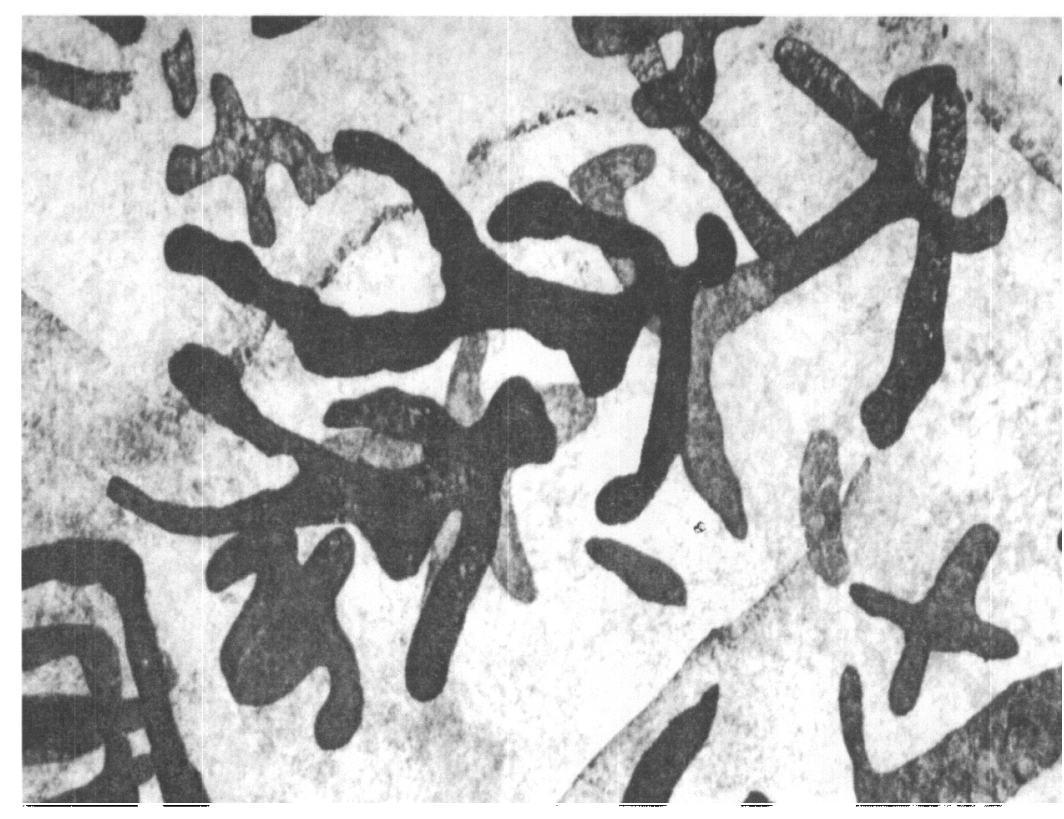

O "Livro d'Isso", de 1921(Groddeck1984), e "Condicionamento Psíquico e Tratamento de Moléstias Orgânicas pela Psicanálise", de 1917 (Groddeck 1992). Uma das tarefas fundamentais para a Psicanálise contemporânea é resgatar a contribuição desse original e perturbador autor, ainda desconhecido e relegado.
Não há aqui espaço suficiente para um desdobramento mais amplo dessa diferenciação, mas ela é fundamental para podermos considerar o modelo a seguir.

\section{A Banda de Moebius}

Em 1861 o matemático Ferdinand Moebius publicou um trabalho em que explorava as características paradoxais de um objeto, que ele definia como "unilátero e nãodirecionável"(Trillat, 1991,pp276-277). Fisicamente sua construção é bastante simples: toma-se uma tira de papel, colam-se suas extremidades, procedendo-se antes, no entanto, a uma torção no sentido longitudinal da tira. Forma-se assim uma espécie de anel, que lembra um oito. Essa figura matemática continua intrigando até hoje os matemáticos, que consideram não ter ainda esgotado o estudo de todas as suas possibilidades.

Do que se trata, e quais são suas utilidades para o tema que nos concerne? Trata-se de uma figura onde se processa uma continuidade completa, onde não existe interior e exterior, e seu uso em Psicanálise deve-se a Jacques Lacan (1973). Aqui propomos um uso um tanto diferente do que Lacan propôs, embora sem dúvida seja dele o essencial dessa apreensão.

Banda é uma folha de papel que não tem frente e verso, possui um único lado. Esse lado, quando percorrido, conduz ao outro. Em seu conjunto, não se pode dizer onde é a frente, onde é o alto, onde é o fundo ou o baixo. Não tem dentro nem fora. Não se orienta no espaço, ou se orienta igualmente, como um objeto mergulhado em espaço topológico. Se ela é cortada, desfazem-se suas propriedades, mas se ela for cortada longitudinalmente, em sua "alma" (é o termo matemático) formam-se duas faixas: uma orientável, com dentro e fora, e outra Banda de Moebius, não orientável.

Para a Psicossomática ela é a representação ideal para configurar-se um modelo para a relação entre o corpo e a mente. O corpo não é o exterior, sendo a mente o seu interior. Os processos psíquicos não são "dentro" do homem. $\mathrm{O}$ "corpo" não lhe é um mero veículo, 
ou uma veste, ou um calçado. O corpo e a mente interpenetram-se, como desde sempre se sabe. Não há processos puramente orgânicos, e nem unicamente mentais. Embora se devam respeitar as especificidades dos registros, havendo assim uma esfera biológica, uma esfera físico-química, dimensões simbólicas organizadas por esferas sociais e culturais, e uma esfera própria ao psiquismo, além de outras, há contudo, uma evidente continuidade no fenômeno humano. Essa continuidade é o que a Banda de Moebius pode dar conta de representar.

O sofrimento humano é uma extraordinária manifestação da unidade da vida humana. Não se sofre só no corpo, nem apenas psiquicamente. O único corpo puro, isolado de mente, é o do cadáver. Os processos psíquicos são "apoiados", como dizia Freud. Talvez não hajam dicotomias, mas apenas modelos distintos de apreensão. O que parece especificamente orgânico no corpo, talvez seja apenas um dos "momentos" da faixa, e se tivéssemos paciência suficiente, sabedoria suficiente, e critérios adequados, possivelmente poderíamos perceber quando esse processo passa a se manifestar em seu "momento" psíquico. De qualquer forma, a Banda de Moebius é um interessante recurso para que possamos nos defrontar com o ser humano integral que vai procurar auxílio para seu sofrimento. Para a clínica psicanalítica trata-se de uma representação que possibilita a continuidade da investigação, sem ruptura, quando é o corpo quem está "falando". Doenças continuarão, obviamente, sendo tratadas por médicos. Conflitos continuarão a ser a matéria prima da investigação dos analistas, mas o fenômeno psicossomático pode, talvez, deixar de ser "terra de ninguém".

Lazslo Antonio Ávila Rua Raul Silva, 615 CEP: 15014-300 São José do Rio Preto-SP

Lopes, O. C. (1970). A medicina no Tempo. Săo Paulo: Melhoramentose EDUSP.

Ariès. P. (1986). História Social da Criança e da Família. Rio de Janeiro: Guanabara.

Etmüller (1986). Pratique de Médecine Spéciale, Lyon).Em Foucault M. (1972). História da Loucura na ldade Clássica.

São Paulo: Perspectiva, 222

Trillat, E. (1991). História da Histeria. São Paulo: Escuta.

Groddeck, G. (1984). O Livro d'lsso. São Paulo: Perspectiva
Groddeck, G. (1992). Condicionamento Psíquico e Tratamento de Moléstias Orgânicas pela Psicanálise.EmGroddeck, G. Estudos psicanalíticos sobre psicossomática, São Paulo: Perspectiva. (Originalmente publicado em 1917).

Lacan, J. (1962). Lidentification. Seminário inédito.

Lacan I. (1973). L'étoudit. Em Scilicet, n"4, Paris: Seul.
Referências bibliográficas 